\title{
54. Karyotypes of Two Representative Species of Hynobiid Salamanders, Hynobius nebulosus (Schlegel) and Hynobius naevius (Schlegel)
}

\author{
By Takeshi Seto,*) Yasuaki Utsunomiya, **) \\ and Taeko UtsunomiYA**) \\ (Communicated by Sajiro Makino, M. J. A., Sept. 12, 1983)
}

Members of the family Hynobiidae are mainly distributed over the eastern Asia and are considered to be the most primitive of the living Caudata on the basis of their external morphology, ecology, life history and karyology (Noble 1931; Morescalchi 1975; Sessions et al. 1982). According to the Makino's list (1956), the chromosome observations of hynobiid salamanders have been undertaken in 15 species based on the testis-sectioning method during from 1930 to the end of 1940. However a few detailed karyotype analyses of these species have been adequately done since the earlier works, mainly due to some difficulty of securing living materials in recent years and of obtaining mitotic cells for the cytological preparations from the adult animals.

Because of their unique ecological and life-history patterns, the hynobiids have much of karyological interest when we consider the amphibian cytotaxonomy and karyoevolution.

As described by Dunn (1923) and Sato (1943), members of the major genus Hynobius, most of them are endemic to Japan, are divided into two groups according to their ecological and morphological features: Some Hynobius species inhabit in the mountain region which primarily spawn in cool streams, while some are living in the lowland where they spawn in small ponds. This paper deals with the karyotypes of two representative species of these groups of Hynobius naevius of the mountain-brook type and $H$. nebulosus of the pond-type, whose cytogenetics have not been studied fully.

Materials and methods. Both of adult male and female specimens provided materials for the present study. Four individuals of Hynobius naevius were procured in Yuki-cho, Hiroshima-ken, and six specimens of $H$. nebulosus were collected in Daito-cho and Matsueshi, Shimane-ken. The animals were injected with a colchicine so-

*) Department of Biology, Faculty of Education, Shimane University. Matsue, 690 Japan.

**) Faculty of Applied Biological Science, Hiroshima University, Fukuyama, 720 Japan. 
lution intraperitoneally at $0.1 \mathrm{ml}$ of the $2 \mathrm{mg} / \mathrm{ml}$ solution per gram of body weight, and were kept in a cool water at $13^{\circ} \mathrm{C}$ for $24 \mathrm{hr}$. The entire gut tract was isolated from the dissected animals and fixed in an acetic alcohol mixture after the $30 \mathrm{~min}$ treatment with the hypotonic solution $(0.075 \mathrm{M} \mathrm{KCl}, \mathrm{pH}$ adjusted 7.0$)$. Somatic chromosomes were prepared from the epithelial cells according to the method of Kezer and Sessions (1979). Chromosomes were stained with the conventional Giemsa-stain. Nomenclature and abbreviations with regard to the shape of chromosomes are those proposed by Levan et al. (1964).

Results. The chromosome number of $H$. nebulosus and $H$. naevius here studied was $2 \mathrm{n}=56$ in both species, confirming the earlier works of Makino (1934), Sato (1936), Ikebe and Kohno (1979a) for $H$. nebulosus, and Makino (1939) for $H$. naevius. It is the same chromosome-number with that of the majority of species examined in the genus Hynobius endemic to Japan, with an exception of $H$. retardatus ( $2 \mathrm{n}=40$; Makino 1932; Azumi and Sasaki 1971). The chromosome morphology, however, was recognized to be unlike between two species.

The karyotype of $H$. nebulosus (Fig. 1) : Twenty-eight pairs of chromosomes in the complement were classified into four groups to facilitate the comparison with the karyotypes of other species. A large-sized chromosomes in the first group included 6 metacentric pairs (nos. 1, 2, 3, 5, 6, and 9) and 3 submetacentric pairs (nos. 4, 7 , and 8 ). The second group comprised 4 medium-sized chromosomes (nos. 10-13) consisting of 1 pair of acrocentric, 2 pairs of submetacentric and 1 pair of metacentric elements. The third and fourth groups contained small-sized chromosomes. The meta- and submetacentric chromosomes were placed in the third group (nos. 14-18), while acrocentric elements in the fourth group (nos. 19-28).

The karyotype of $H$. naevius (Fig. 2) : The general features of the chromosome constitution were almost identical with that of $H$. nebulosus. The four chromosome groups contained 9 large-sized pairs (nos. 1-9), 4 medium-sized pairs (nos. 10-13), and 15 small-sized pairs (14-28).

In comparing the chromosome morphology in the two karyotypes it was noted that an obvious difference occurred in the second group as shown in Figs. 1 and 2. H. naevius bore 3 submetacentric and 1 metacentric pairs, in contrast to $H$. nebulosus which comprised 1 acrocentric, 2 submetacentric and 1 metacentric pairs in the group. The remaining 9 large-sized (nos. 1-9) and 15 small-sized (nos. 1428) chromosomes of both naevius and nebulosus seemed to be identical in morphology in the present observations. As a consequence of 
the foregoing description, two karyotypes led the different fundamental number (FN) in the two species, 90 for $H$. nebulosus and 92 for $H$. naevius.
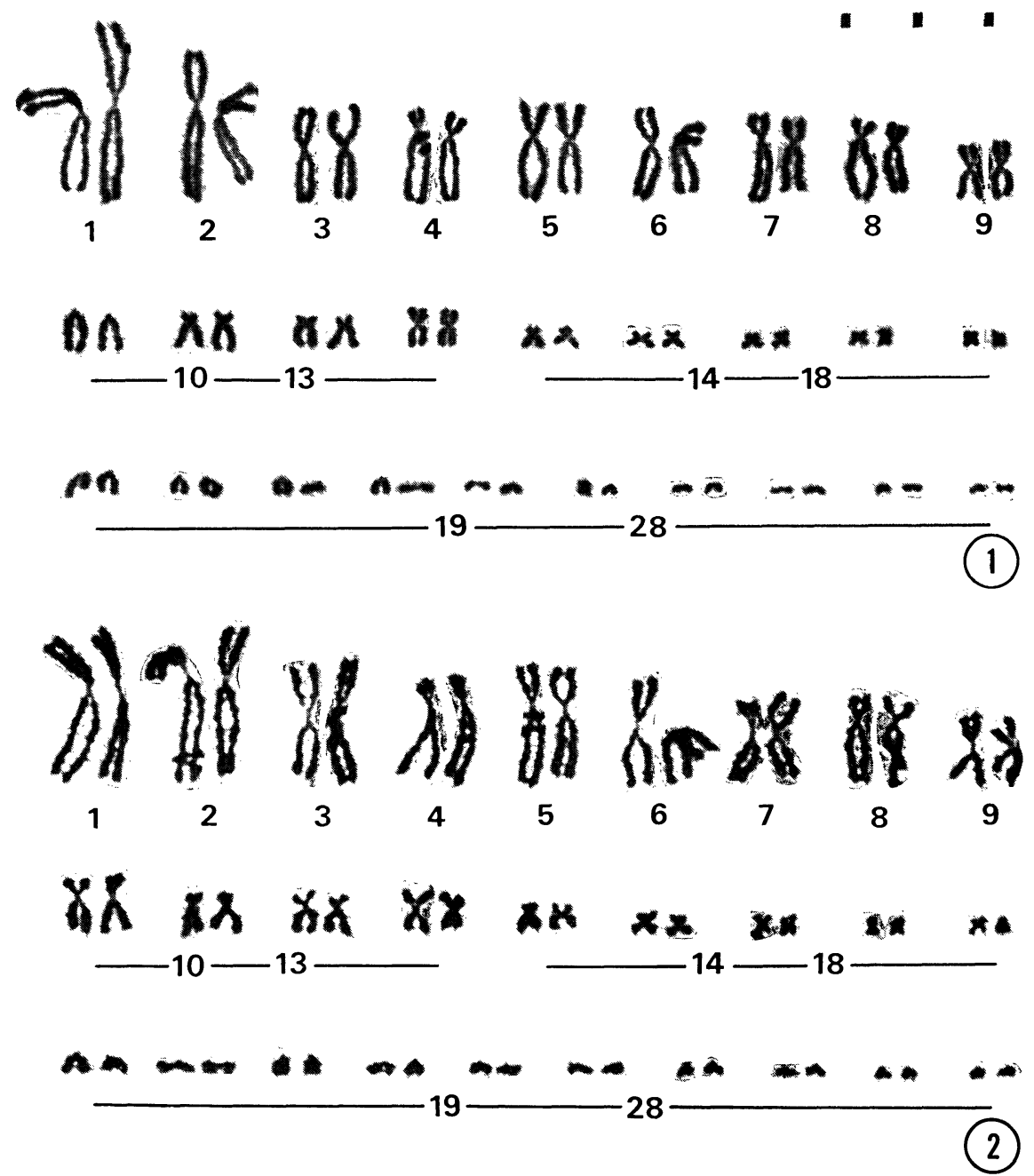

Figs. 1 and 2. Karyotypes of Hynobius nebulosus 우 (1), and Hynobius naevius $\hat{\circ}$ (2); each showing 56 chromosomes. Giemsa stain. Scale: 1 division $=10 \mu \mathrm{m}$.

So far as we examined in the adult specimens of both species, male and female karyotypes were identical and no heteromorphic pair of chromosomes identified as the sex element was detected in both species.

Discussion. There have been four papers describing the karyo- 
types of the genus Hynobius observed with the squashed or air-dried techniques (Azumi and Sasaki 1971; Ikebe and Kohno 1979a, 1979b; Morescalchi et al. 1979). Most of species examined of the genus Hynobius have generally a uniform karyotype consisting of $2 n=56$ chromosomes. Among the previous workers, studied by Ikebe and Kohno (1979a, 1979b) presented authentic karyograms of four species, such as $H . n$. nebulosus, $H . n$. tokyoensis (now commonly named as $H$. nebulosus and $H$. tokyoensis), $H$. lichenatus, and $H$. nigrescens. Their illustrations, based on the larval tissues, of the respective karyotype supplied a sufficient information for comparing with the karyograms of $H$. nebulosus and $H$. naevius presented in this paper.

A karyotypical difference between $H$. naevius and $H$. nebulosus has been characterized by 4 pairs of medium-sized chromosomes (nos. 10-13), with special regard to no. 10 pair as submetacentrics of $H$. naevius, while as acrocentrics of $H$. nebulosus. With regard to this character, it seems that $H$. naevius of the mountain-brook type has much similar karyotype with those of $H$. nigrescens and $H$. lichenatus which are the pond-type. Thus, the karyological character does not coincide with those of an ecological grouping of hynobiids as described by Sato (1943) as the mountain-brook type and the pondor lowland-type.

A minor dissimilarity has been found in the small-sized group of the $H$. nebulosus karyotype between the present result and the previous study by Ikebe and Kohno (1979a). They described 7 pairs of meta- and submetacentric chromosomes in the third group and 8 pairs of acrocentrics in the fourth group. In contrast, we observed 5 pairs of meta- and submetacentrics, and 10 pairs of acrocentric chromosomes in respective groups. The difference of the chromosome constitution in the third and fourth group, conventionally called microchromosomes (Morescalchi 1975), indicated a difference of the fundamental number between these two observations of the same species, and that arises another interesting question. It is wellknown that $H$. nebulosus is the most common species of the pond-type and is widely distributed in the western Japan with some local variations of its morphological and physiological characters (Sato 1937; Ebitani 1952; Kawamura 1956). According to Kawamura (1956), $H$. nebulosus consisted of four local races and their intraspecificcross experiments among four local races indicated that the hybrid inviability, hybrid weakness and hybrid sterility could be occurred in some of these crosses.

The karyological difference in $H$. nebulosus of the present observations from that of Ikebe and Kohno (1979a) suggests a varia- 
tion occurring in the microchromosomal constitution according to the difference of the locality. More cytogenetic study has thus been required to lead the conclusion of this interesting problem.

Summary. Somatic chromosomes of two representative species of the genus Hynobius are observed. The diploid number of $H$. naevius and $H$. nebulosus are confirmed to have 56. Twenty-eight pairs of homologues are classified into four groups to facilitate the comparison of each karyotype. The chromosome morphology constituting both karyotypes is similar in general, but not identical with each other. An unambiguous difference occurs in the medium-sized chromosomes (nos. 10-13). Consequently, it results the different fundamental number (FN) to two species, 90 for $H$. nebulosus and 92 for $H$. naevius. The karyotype of $H$. nebulosus, which is the most common species and is widely distributed in the western Japan, is not exactly the same with that of a previous work. The minor difference found in the small-sized chromosome groups (nos. 14-18 and 19-28) suggests the microchromosomal variation according to the difference of the locality.

Acknowledgement. The authors are deeply indebted to Professor Emeritus Sajiro Makino, M. J. A., for the improvement of this manuscript with invaluable advice.

\section{References}

Azumi, J., and Sasaki, M. (1971) : CIS, 12, 31-32.

Dunn, E. R. (1923) : Proc. Amer. Acad. Arts Sci., 58, 445-523.

Ebitani, Y. (1952) : J. Sci. Hiroshima Univ., ser. B, 13, 173-184.

Ikebe, C., and Kohno, S. (1979a) : Proc. Japan Acad., 55B, 436-440.

- (1979b) : CIS, 27, 13-15.

Kawamura, T. (1956): Population Genetics (eds. Komai, T., and Sakai, K.). Baifukan, Tokyo, pp. 143-162 (in Japanese).

Kezer, J., and Sessions, S. K. (1979) : Chromosoma, 71, 65-80.

Levan, A., Fredga, K., and Sandberg, A. A. (1964) : Hereditas, 52, 201-220.

Makino, S. (1932) : J. Fac. Sci., Hokkaido Imp. Univ., ser. IV, 2, 97-109.

- (1934) : Trans. Sapporo Nat. Hist. Soc., 13, 351-354. (1939) : Zool. Mag. (Tokyo), 51, 729-733 (in Japanese).

(1956): A Review of the Chromosome Numbers in Animals. Rev. ed., Hokuryukan, Tokyo, pp. 142-147.

Morescalchi, A. (1975) : Evolutionary Biology. vol. 8 (eds. Dobzhansky, T., Hecht, M. K., and Steere, W. C.), Plenum Publ. Co., N.Y., pp. 339-387.

Morescalchi, A., Odierna, G., and Olmo, E. (1979) : Experientia, 35, 1434-1435. Noble, G. K. (1931) : The Biology of the Amphibia. Dover Publ. Inc., N.Y., p. 577.

Sato, I. (1936) : J. Sci. Hiroshima Univ., ser. B., 4, 143-154.

- (1937): Fauna Nipponica. vol. 15, fas. III, no. 1, Sanseido, Tokyo, p. 74 (in Japanese).

- (1943): A Monograph on the Japanese Urodeles. Japan Press, Osaka, p. 520 (in Japanese).

Sessions, S. K., Leon, P. E., and Kezer, J. (1982) : Chromosoma, 86, 341-357. 